\title{
Multi-Responsive Polymethacrylamide Homopolymers Derived from Tertiary
}

\section{Amine-Modified $L$-Alanine}

\author{
Chunhui Luo, ${ }^{\mathrm{a}, \mathrm{b}^{*}}$ Wenxin Fu, ${ }^{\mathrm{b}}$ Zhibo $\mathrm{Li}^{\mathrm{c}^{*}}$ and Bin Zhao ${ }^{\mathrm{b} *}$
}

${ }^{a}$ College of Chemistry and Chemical Engineering, Beifang University of Nationalities, Yinchuan, Ningxia 750021, China

${ }^{\mathrm{b}}$ Department of Chemistry, University of Tennessee, Knoxville, Tennessee 37996, United States

${ }^{\mathrm{c}}$ School of Polymer Science and Engineering, Qingdao University of Science and Technology, Qingdao, Shandong 266042, China

*Corresponding Author. Email: 1uochunhui@iccas.ac.cn, zbli@qust.edu.cn, bzhao@utk.edu

\begin{abstract}
Four poly( $N$-methacryloyl- $L$-alanine $)$ homopolymers containing different tertiary amine moieties, dimethylaminoethyl, dimethylaminopropyl, diethylaminoethyl, and diethylaminopropyl, were prepared by reversible addition-fragmentation chain transfer (RAFT) polymerization in an effort to use natural amino acids as building blocks to design stimuli-responsive polymers that display $\mathrm{pH}$-tunable lower critical solution temperature (LCST) transitions in the basic $\mathrm{pH}$ range. Monomer structure was found to be critical for the corresponding polymer to exhibit desired stimuli-responsive properties in water. While all four
\end{abstract}


polymethacrylamides showed thermosensitive property in water, only poly $(N$-methacryloyl- $L$-alanine 2-(diethylamino)ethylamide) (PMAEE) exhibited LCST behavior in a wide $\mathrm{pH}$ range, from 9.0 to 13.0 . Other polymers' thermoresponsive properties were found either at very high $\mathrm{pH}$ values (e.g., $\geq 13.0$ ) or in a rather narrow $\mathrm{pH}$ range. The effects of $\mathrm{pH}$, polymer molecular weight, polymer concentration, presence of $\mathrm{NaCl}$, and end groups on cloud point of PMAEE in water were investigated; the cloud point decreased with the increase of solution $\mathrm{pH}$ and polymer concentration, the addition of $\mathrm{NaCl}$, and the introduction of a more hydrophobic end group but varied little with polymer molecular weight. The incorporation of tertiary amine moieties endowed the polymers with a $\mathrm{CO}_{2}$-responsive property; we demonstrated that the thermosensitive property of PMAEE can be reversibly tuned by bubbling its solution alternately with $\mathrm{CO}_{2}$ and $\mathrm{N}_{2}$ gases.

Keywords: Amino acid, Thermo-responsive, Lower critical solution transition. 


\section{Introduction}

Stimuli-responsive polymers can undergo reversible or irreversible changes in polymer conformations, chemical structures, or physical properties in response to external stimuli such as temperature, $\mathrm{pH}$, light, or specific molecular species. These smart materials have potential applications ranging from drug delivery to tissue engineering, catalysis, and nanotechnology [1-5]. Among them, thermosensitive water-soluble polymers that exhibit a lower critical solution temperature (LCST) in water have been intensively studied both fundamentally and practically; examples of such polymers include poly( $N$-isopropylacrylamide) (PNIPAM) [4], poly((oligo(ethylene oxide) (meth)acrylate)s [6], pyrrolidone-based polymers [7-9], and polypeptides [10-13]. Of particular interest are thermo- and $\mathrm{pH}$-sensitive polymers $[2,3,14,15]$, these dually responsive polymers can provide greater flexibility in the design of polymeric systems for, e.g., drug delivery, and can be employed to mimic biological processes, which are often triggered by multiple external stimuli instead of a single one. Thermo- and pH-responsive polymers typically bear weak acid (e.g., -COOH) or base (e.g., tertiary amines) moieties, and their LCSTs depend on the degree of ionization of the weak acid or base moiety. They are usually prepared by random copolymerization of different monomers that have distinct functions in the polymers. However, the monomers may have very different reactivity ratios, and the distribution of different monomer units along the random copolymer chain may affect the thermoresponsive property. An alternative approach is to combine different groups into one monomer, which can be polymerized to produce a homopolymer and thus avoids the problem in the copolymerization of 
multiple monomers.

Using natural materials such as amino acids or polypeptides as building blocks to design and prepare responsive and functional polymeric materials have many advantages including biocompatibilities, higher-ordered structures, and optical activity [16-27]. In particular, vinyl monomers bearing $\alpha$-amino acids and their derivatives have gained considerable interest in recent years, owing to the prospect of using "living"/controlled radical polymerization to synthesize well-defined polymers. For example, Endo et al. developed thermoresponsive (co)polymers containing $N$-acryloyl- $L$-proline methyl ester, poly(A-Pro-OMe) [16, 18]. McCormick and coworkers synthesized and studied the self-assembly behavior of $\operatorname{poly}(N$-acryloyl-alanine) and poly( $N$-acryloyl-valine) block copolymers [20, 21]. O'Reilly group prepared amino acid-derived diblock copolymers by reversible addition-fragmentation chain transfer (RAFT) polymerization and investigated their self-assembly behaviors; they found that the diblock copolymers could form spherical micelles with relatively narrow dispersities [22, 23]. We previously reported dual thermo- and $\mathrm{pH}$-sensitive homopolymers made from aspartic acidand alanine-containing methacrylamides with the $N$-terminal capped with amide or ester moieties [25-27]. Interestingly, we observed that the cloud points of poly( $N$-methacryloyl- $L$-alanine isopropyl amide) and poly( $N$-methacryloyl- $L$-alanine methyl ester $)$ at similar degrees of polymerization (DPs) were almost the same, suggesting that the methyl ester group had similar hydrophilicity contribution as the isopropyl amide group [26]. Besides individual amino acids, oligopeptides, usually a VPGVP pentapeptide sequence, have also been employed to construct 
thermoresponsive polymers [28, 29]. We note here that thus far the reported thermo- and pH-sensitive amino acid-derived homopolymers display $\mathrm{pH}$-tunable LCSTs only in acidic water due to the nature of the carboxyl acid. Considering the widespread use of thermosensitive water-soluble polymers, it is relevant and of significance to expand the thermoresponsive behavior to the basic $\mathrm{pH}$ range.

Much like carboxylic acid-containing thermosensitive water-soluble polymers displaying a pH-tunable LCST in acidic water, tertiary amine-based homopolymers could exhibit $\mathrm{pH}$-dependent LCST behavior in water in the basic $\mathrm{pH}$ range if an appropriate hydrophilic/hydrophobic balance is achieved among backbone, side chain, and tertiary amine moieties [30-38]. For example, poly( $N, N$-dimethylaminoethyl methacrylate) (PDMAEMA) has a cloud point of around $50{ }^{\circ} \mathrm{C}$ at $\mathrm{pH}=8$ and the cloud point decreases with increasing $\mathrm{pH}[30,32]$. Lee et al. introduced primary and tertiary amines into the side chain of poly(2-hydroxyethyl methacrylate); the resultant polymers showed thermosensitivity in a very narrow pH range [33]. More recently, Huang et al. reported thermo- and $\mathrm{pH}$-responsive homopolymer bearing oligo(ethylene glycol) unit and $N, N$-diethylamino ethyl group [35]. We also note here that one advantage of incorporating tertiary amine moieties into the thermosensitive water-soluble polymers is that $\mathrm{CO}_{2}$ gas can also be used as a $\mathrm{pH}$ stimulus to adjust the cloud point of the polymer [39]. Despite the progress, the reported multi-sensitive homopolymers are rather limited, and none of them contains amino acids and derivatives, for most of the tertiary amine-based polymers are only $\mathrm{pH}$-sensitive $[3,31,40]$. 
Herein we reported a series of novel homopolymers derived from $L$-alanine and tertiary amines (Scheme 1) that exhibited $\mathrm{pH}$-tunable cloud points in water in the basic $\mathrm{pH}$ range. $L$-Alanine was used as a chiral center and its $N$-terminal was bonded to the polymerizable methaycryloyl group through an amide linkage. The carboxylic acid terminal of $L$-alanine was capped also via an amide linkage with various tertiary amine groups: 2-dimethylaminoethyl, 3-dimethylaminopropyl, 2-diethylaminoethyl, and 3-diethylaminopropyl. These $L$-alanine-derived homopolymers were prepared by RAFT polymerization, and their stimuli-responsive properties in water were studied by visual inspection, dynamic light scattering, and variable temperature ${ }^{1} \mathrm{H}$ NMR spectroscopy. We found that their thermosensitive properties in water were dependent on their chemical structures and slight variations of monomer structures can dramatically change their stimuli-responsive properties. In addition, the introduction of tertiary amine moieties endows the polymers with a $\mathrm{CO}_{2}$-responsive property. As an example, we demonstrated that the thermoresponsive property of poly $(N$-methacryloyl- $L$-alanine 2-(diethylamino)ethylamide) (PMAEE, Scheme 1) can be reversibly tuned by bubbling alternately with $\mathrm{CO}_{2}$ and $\mathrm{N}_{2}$. The design principle reported here will also take advantage of natural amino acids, which can provide additional functionality, optical activity, and tunable side groups. These additional features might offer more potential applications for these amino acid derived thermoresponsive polymers. 


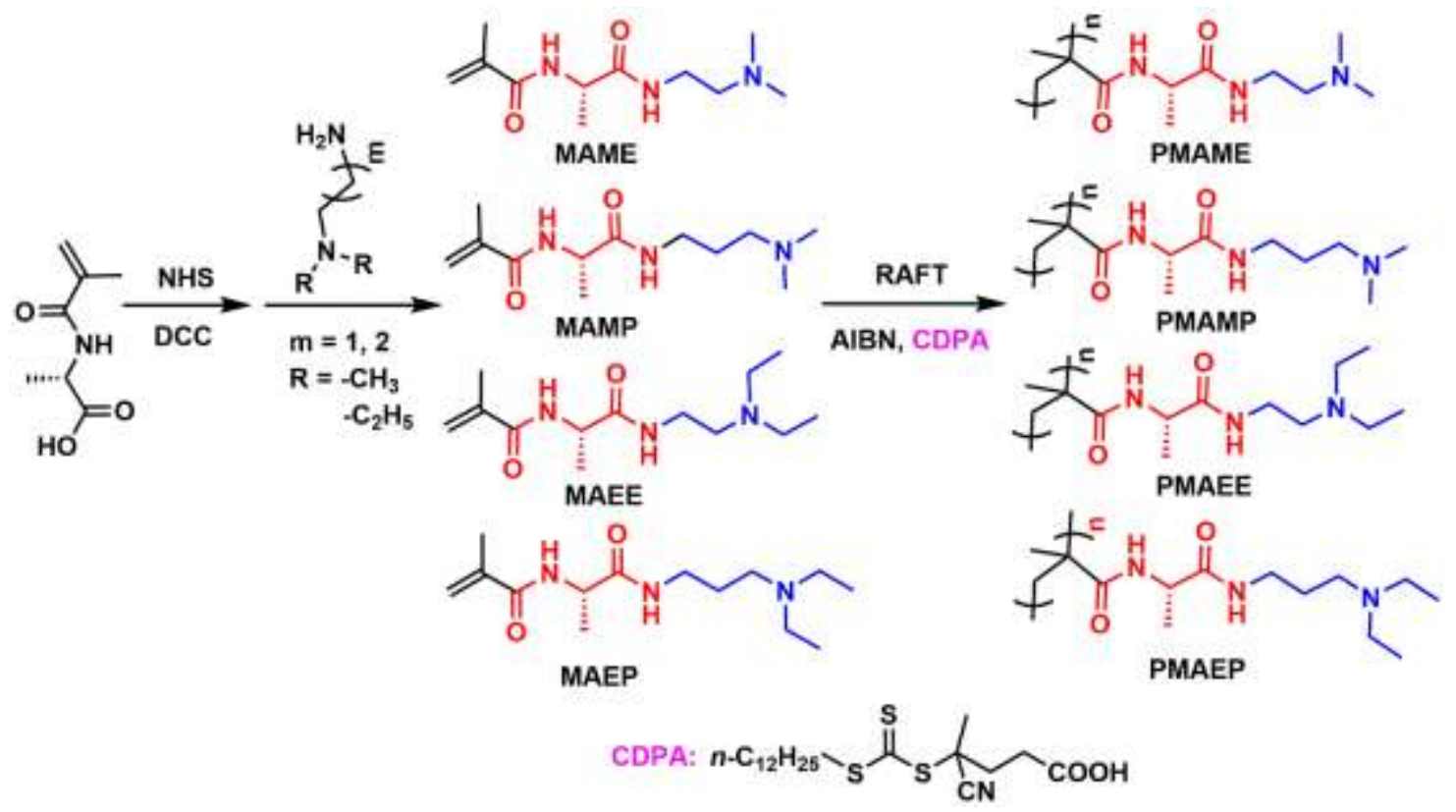

Scheme 1. Synthesis of tertiary amine-modified $L$-alanine-based methacrylamides and corresponding polymethacrylamide homopolymers prepared by reversible addition-fragmentation chain transfer polymerization.

\section{Experimental section}

\subsection{Materials}

L-Alanine (L-Ala), methacryloyl chloride (98\%), 2-(dimethylamino)ethylamine, 3-(dimethylamino)-1-propylamine, 2-(diethylamino)ethylamine, 3-(diethylamino)-1-propylamine, dicyclohexylcarbodiimide (DCC), $\mathrm{N}$-hydroxysuccinimide (NHS), and $\mathrm{Na}_{2} \mathrm{CO}_{3}$ were purchased from Fisher Scientific and used as received. 2,2'-Azobis(isobutyronitrile) (AIBN) was purified by recrystallization from methanol. Tetrahydrofuran (THF) was dried with and distilled from sodium and benzophenone and used immediately. Three RAFT chain transfer agents, 4-cyano-4-(dodecylsulfanylthiocarbonyl)sulfanylpentanoic acid

(CDPA), 4-cyano-4-(butylsulfanylthiocarbonyl)sulfanylpentanoic acid (CBPA), and 2-cyanoprop-2-yl 
butyl trithiocarbonate (CBTB) shown in Schemes 1 and S1 were synthesized following the procedures reported in the literature [41], and their molecular structures were confirmed by ${ }^{1} \mathrm{H}$ NMR spectroscopy analysis. $N$-Methacryloyl- $L$-alanine (Ma-Ala-OH) was prepared by reacting equal molar methacryloyl chloride with $L$-alanine in basic water in the presence of $\mathrm{Na}_{2} \mathrm{CO}_{3}$, and the molecular structure was verified by ${ }^{1} \mathrm{H}$ NMR spectroscopy analysis [26]. All other chemical reagents were purchased from either Fisher or Sigma and used without further purification.

\subsection{General Characterization}

${ }^{1} \mathrm{H}$ and ${ }^{13} \mathrm{C}$ NMR spectra were recorded on a Varian Mercury 300 NMR spectrometer, and the residual solvent proton signal was used as the internal reference. Variable temperature ${ }^{1} \mathrm{H}$ NMR spectroscopy analysis was conducted on a Varian VNMRS $500 \mathrm{MHz}$ spectrometer. High resolution mass spectroscopy (HRMS) experiments were performed using a JEOL Model JMS-T100LC (AccuTOF) orthogonal time-of-flight (TOF) mass spectrometer (Peabody, MA) with an IonSense (Danvers, MA) DART source. Circular dichroism (CD) spectroscopy was conducted on an Aviv $202 \mathrm{CD}$ spectrophotometer at room temperature. Size exclusion chromatography (SEC) was carried out at ambient temperature using PL-GPC 50 Plus, an integrated GPC/SEC system from Polymer Laboratories, Inc., composed of a Waters 510 pump, a Knauer Smartline 2300 RI detector, one PLgel $10 \mu \mathrm{m}$ guard column $(50 \times 7.5 \mathrm{~mm}$, Agilent Technologies), and three PLgel $10 \mu \mathrm{m}$ mixed-B columns in series (each $7.5 \times 300 \mathrm{~mm}$, Agilent Technologies, Inc.). HPLC grade $N, N$-dimethylformamide (DMF) with $50 \mathrm{mM} \mathrm{LiBr}$ was used as the mobile phase with a flow rate of $1.0 \mathrm{~mL} \mathrm{~min}^{-1}$. The system was calibrated with polystyrene 
standards, and the data were processed using Cirrus GPC/SEC software. The $\mathrm{pH}$ values of polymer aqueous solutions were measured at ambient temperature with a $\mathrm{pH}$ meter (Accumet AB15 $\mathrm{pH}$ meter from Fisher Scientific, calibrated with $\mathrm{pH}=4.01,7.00$, and 10.01 standard buffer solutions), and the $\mathrm{pH}$ of the polymer solution was adjusted using $0.1 \mathrm{M} \mathrm{HCl}$ or $2.5 \mathrm{M}$ $\mathrm{NaOH}$ solutions.

\subsection{Synthesis of Tertiary Amine-Modified L-Alanine-Containing Methacrylamide Monomers}

Four different tertiary amine-modified $L$-alanine-containing methacrylamide monomers were synthesized using a two-step procedure. Firstly, Ma-Ala-OH was reacted with $N$-hydroxysuccinimide (NHS) in THF to form an activated ester using dicyclohexylcarbodiimide (DCC) as catalyst, which was then reacted with $\alpha$-primary $\omega$-tertiary amines to give target monomers. Described below is the synthesis of monomer MAEE, serving as an example. Ma-Ala-OH (10.000 g, $63.66 \mathrm{mmol})$ and NHS (8.793 g, $76.40 \mathrm{mmol})$ were dissolved in anhydrous THF $(200 \mathrm{~mL})$ with magnetic stirring bar in a $500 \mathrm{~mL}$ three-necked round bottom flask. The flask was then placed in an ice/water bath, and dicyclohexylcarbodiimide (15.764 g, $76.40 \mathrm{mmol})$ dissolved in anhydrous THF $(50 \mathrm{~mL})$ was added under the conditions of vigorous stirring. After the mixture was stirred at ambient temperature for $24 \mathrm{~h}$, the precipitate was removed by filtration and the filtrate was concentrated by evaporating THF using a rotary evaporator, followed by dropwise addition of 2-(diethylamino)ethylamine (7.397 g, $63.66 \mathrm{mmol})$ into the filtrate in an ice/water bath. The resultant mixture was stirred at room temperature overnight. THF was then removed by rotary evaporation, and the crude product was 
purified by column chromatography using a mixture of methanol and dichloromethane $(1 / 10, \mathrm{v} / \mathrm{v})$ as eluent to give $N$-methacryloyl- $L$-alanine 2-(diethylamino)ethylamide (MAEE) monomer as a white solid (6.612 g, $40.7 \%$ yield). ${ }^{1} \mathrm{H}$ NMR (300 MHz, $\left.\mathrm{CDCl}_{3}, \mathrm{TMS}\right): \delta=6.53(\mathrm{CONH}, 2 \mathrm{H}, \mathrm{b})$,

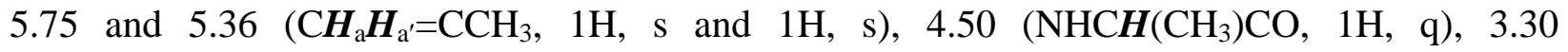
$\left(\mathrm{NHCH}_{2} \mathrm{CH}_{2} \mathrm{~N}, 2 \mathrm{H}, \mathrm{m}\right), 2.52\left(\mathrm{CH}_{2} \mathrm{CH}_{2} \mathrm{~N}\left(\mathrm{CH}_{2} \mathrm{CH}_{3}\right)_{2}, 6 \mathrm{H}, \mathrm{m}\right), 1.97\left(\mathrm{CH}_{2}=\mathrm{CCH}_{3}, 3 \mathrm{H}, \mathrm{s}\right), 1.41$

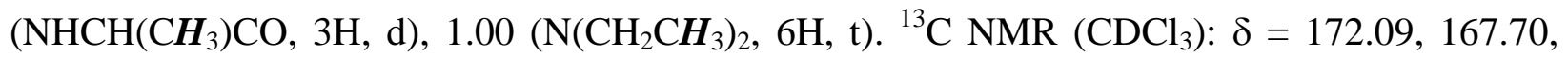
139.41, 120.23, 51.22, 48.89, 46.71, 36.82, 19.02, 18.50, and 11.65. HRMS: $\mathrm{m} / \mathrm{z}$ calcd for $\mathrm{C}_{13} \mathrm{H}_{25} \mathrm{~N}_{3} \mathrm{O}_{2}[\mathrm{M}+\mathrm{H}]^{+}: 256.2025$; found: 256.2034 .

$N$-Methacryloyl- $L$-alanine 2-(dimethylamino)ethylamide (MAME), $N$-methacryloyl- $L$-alanine $\quad 3$-(dimethylamino)propylamide $\quad$ (MAMP), and $N$-methacryloyl- $L$-alanine 3-(diethylamino)propylamide (MAEP) were synthesized via the same procedure using the corresponding amines.

MAME (white solid, $45.9 \%$ yield). ${ }^{1} \mathrm{H}$ NMR (300 MHz, $\left.\mathrm{CDCl}_{3}, \mathrm{TMS}\right): \delta=6.56$ (CONH,

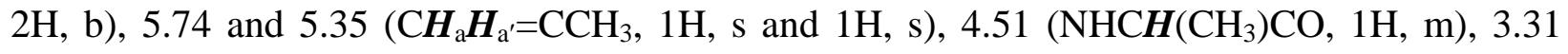
$\left(\mathrm{CONHCH}_{2} \mathrm{CH}_{2} \mathrm{~N}, 2 \mathrm{H}, \mathrm{t}\right), 2.40\left(\mathrm{CONHCH}_{2} \mathrm{CH}_{2} \mathrm{~N}\left(\mathrm{CH}_{3}\right)_{2}, 2 \mathrm{H}, \mathrm{t}\right), 2.22\left(\mathrm{CH}_{2} \mathrm{~N}\left(\mathrm{CH}_{3}\right)_{2}, 6 \mathrm{H}, \mathrm{m}\right)$, $1.96\left(\mathrm{CH}_{2}=\mathrm{CCH} \boldsymbol{H}_{3}, 3 \mathrm{H}, \mathrm{s}\right), 1.39\left(\mathrm{NHCH}\left(\mathrm{CH}_{3}\right) \mathrm{CONH}, 3 \mathrm{H}, \mathrm{d}\right) \cdot{ }^{13} \mathrm{C} \mathrm{NMR}\left(\mathrm{CDCl}_{3}\right): \delta=172.18$ $167.71,139.45,120.16,57.54,48.82,45.10,36.91,19.02,18.49$. HRMS: $\mathrm{m} / \mathrm{z}$ calcd for $\mathrm{C}_{11} \mathrm{H}_{21} \mathrm{~N}_{3} \mathrm{O}_{2}[\mathrm{M}+\mathrm{H}]^{+}:$228.1712; found: 228.1711.

MAMP (white solid, $41.6 \%$ yield). ${ }^{1} \mathrm{H}$ NMR (300 MHz, $\mathrm{CDCl}_{3}, \mathrm{TMS}$ ): $\delta=7.66$ and 6.63 
$(\mathrm{CONH}, 1 \mathrm{H}, \mathrm{b}$ and $1 \mathrm{H}, \mathrm{b}), 5.81$ and $5.43\left(\mathrm{CH}_{\mathrm{a}} \boldsymbol{H}_{\mathrm{a}^{\prime}}=\mathrm{CCH}_{3}, 1 \mathrm{H}, \quad \mathrm{s}\right.$ and $\left.1 \mathrm{H}, \mathrm{s}\right), 4.41$ $\left(\mathrm{NHCH}\left(\mathrm{CH}_{3}\right) \mathrm{CO}, 1 \mathrm{H}, \mathrm{m}\right), 3.36\left(\mathrm{CONHCH}_{2} \mathrm{CH}_{2}, 2 \mathrm{H}, \mathrm{m}\right), 2.41\left(\mathrm{CH}_{2} \mathrm{CH}_{2} \mathrm{~N}\left(\mathrm{CH}_{3}\right)_{2}, 2 \mathrm{H}, \mathrm{m}\right), 2.26$ $\left(\mathrm{CH}_{2} \mathrm{~N}\left(\mathrm{CH}_{3}\right)_{2}, \quad 6 \mathrm{H}, \quad \mathrm{m}\right), \quad 1.98 \quad\left(\mathrm{CH}_{2}=\mathrm{CCH}_{3}, \quad 3 \mathrm{H}, \quad\right.$ s $), \quad 1.68 \quad\left(\mathrm{CH}_{2} \mathrm{CH}_{2} \mathrm{CH}_{2}, \quad 2 \mathrm{H}, \quad \mathrm{m}\right), \quad 1.39$ $\left(\mathrm{NHCH}\left(\mathrm{CH}_{3}\right) \mathrm{CONH}, 3 \mathrm{H}, \mathrm{d}\right) .{ }^{13} \mathrm{C} \mathrm{NMR}\left(\mathrm{CDCl}_{3}\right): \delta=172.41,167.62,139.09,120.09,57.36$, 48.92, 44.64, 38.14, 28.41, 19.02, 18.50. HRMS: m/z calcd for $\mathrm{C}_{12} \mathrm{H}_{23} \mathrm{~N}_{3} \mathrm{O}_{2}[\mathrm{M}+\mathrm{H}]^{+}: 242.1869$; found:242.1876.

MAEP (white solid, $41.9 \%$ yield). ${ }^{1} \mathrm{H}$ NMR (300 $\left.\mathrm{MHz}, \mathrm{CDCl}_{3}, \mathrm{TMS}\right): \delta=7.97$ and 6.70 $(\mathrm{CONH}, 1 \mathrm{H}, \mathrm{b}$ and $1 \mathrm{H}, \mathrm{b}), 5.85$ and $5.55\left(\mathrm{CH}_{\mathrm{a}} \boldsymbol{H}_{\mathrm{a}^{\prime}}=\mathrm{CCH}_{3}, 1 \mathrm{H}, \quad \mathrm{s}\right.$ and $\left.1 \mathrm{H}, \mathrm{s}\right), 4.47$ $\left(\mathrm{NHCH}\left(\mathrm{CH}_{3}\right) \mathrm{CO}, 1 \mathrm{H}, \mathrm{m}\right), 3.61-3.33\left(\mathrm{CONHCH}_{2} \mathrm{CH}_{2}, 2 \mathrm{H}, \mathrm{m}\right), 3.28-2.96\left(\mathrm{CH}_{2} \mathrm{CH}_{2} \mathrm{~N}\left(\mathrm{CH}_{2} \mathrm{CH}_{3}\right)_{2}\right.$, 6H, m), 2.15-1.92 $\left(\mathrm{CH}_{2} \mathrm{CH}_{2} \mathrm{CH}_{2}, 2 \mathrm{H}, \mathrm{m}\right.$ and $\left.\mathrm{CH}_{2}=\mathrm{CCH}_{3}, 3 \mathrm{H}, \mathrm{s}\right), 1.46\left(\mathrm{NHCH}\left(\mathrm{CH}_{3}\right) \mathrm{CONH}, 3 \mathrm{H}\right.$, d), $1.36\left(\mathrm{~N}\left(\mathrm{CH}_{2} \mathrm{CH}_{3}\right)_{2}, 6 \mathrm{H}, \mathrm{t}\right) .{ }^{13} \mathrm{C} \mathrm{NMR}\left(\mathrm{CDCl}_{3}\right): \delta=173.49,168.21,139.26,120.66,57.27$, 49.79, 45.98, 40.02, 36.02, 18.65, 18.52, 8.32. HRMS: m/z calcd for $\mathrm{C}_{14} \mathrm{H}_{27} \mathrm{~N}_{3} \mathrm{O}_{2}[\mathrm{M}+\mathrm{H}]^{+}$: 270.2182; found: 270.2193 .

\subsection{RAFT Polymerization of MAME, MAMP, MAEE, and MAEP.}

RAFT polymerization was employed to synthesize poly(MAME) (PMAME), poly(MAMP) (PMAMP), poly(MAEE) (PMAEE), and poly(MAEP) (PMAEP). The polymerizations were conducted in isopropanol mainly using CDPA as chain transfer agent (CTA) and 2,2'-azobis(isobutyronitrile) (AIBN) as initiator. The following is a representative RAFT polymerization of MAEE; other polymers were synthesized by a similar procedure. MAEE (510.4 mg, $2.00 \mathrm{mmol})$, CDPA (16.2 mg, $0.040 \mathrm{mmol})$, AIBN (1.64 mg, $0.01 \mathrm{mmol})$, and 
isopropanol $(1.0 \mathrm{~g})$ were added into a $25 \mathrm{~mL}$ two-necked round-bottom flask. The mixture was degassed by three freeze-pump-thaw cycles, and the flask was immersed in a $70{ }^{\circ} \mathrm{C}$ oil bath. ${ }^{1} \mathrm{H}$ NMR spectroscopy and SEC were used to follow the progress of the RAFT polymerization. The flask was removed from the oil bath after $24 \mathrm{~h}$ and a sample was taken immediately for the determination of the monomer conversion by ${ }^{1} \mathrm{H}$ NMR spectroscopy analysis. The monomer conversion was $80.0 \%$, calculated using the following equation: monomer conversion $=\left(I_{3.30^{-}}\right.$ $\left.I_{5.75}-I_{5.36}\right) / I_{3.30}$, where $I_{5.75}$ and $I_{5.36}$ were the integrals of vinyl protons of $\mathrm{CH}_{2}=\mathrm{CCH}_{3}$ in $\mathrm{MAEE}$ and $I_{3.30}$ was the sum of the integrals of the methylene peaks of $-\mathrm{NHCH}_{2} \mathrm{CH}_{2} \mathrm{~N}$ at $3.30 \mathrm{ppm}$ in PMAEE polymer and MAEE monomer at the end of the polymerization. The polymerization mixture was diluted with $\mathrm{DMF}(\sim 2 \mathrm{~mL})$ and then precipitated in diethyl ether $(50 \mathrm{~mL})$ three times. The polymer was collected and dried under high vacuum. SEC analysis results (relative to polystyrene standards): $M_{\mathrm{n}, \mathrm{SEC}}=27.3 \mathrm{kDa}$; polydispersity index $(\mathrm{PDI})=1.31$.

\subsection{Preparation of Aqueous Polymer Solutions with Different pH Values}

Polymers were firstly dissolved in pure water to form a stock solution; then $0.1 \mathrm{M} \mathrm{HCl}$ aqueous solution was used to decrease the $\mathrm{pH}$ while $2.5 \mathrm{M} \mathrm{NaOH}$ aqueous solution was applied to increase the $\mathrm{pH}$ to desired values monitored by a $\mathrm{pH}$ meter, respectively. The following is a typical procedure for the preparation of aqueous solutions of PMAEE; other polymer solutions were made in a similar manner. PMAEE with a DP of $85\left(\mathrm{PMAEE}_{85}\right)(0.100 \mathrm{~g})$ was dried under high vacuum and then dissolved in pure water $(19.90 \mathrm{~g})$ to form a $0.5 \mathrm{wt} \%$ stock solution. A portion of the stock solution (4.0 g) was transferred into a vial and its $\mathrm{pH}$ was adjusted to 11.0 by 
adding $2.5 \mathrm{M} \mathrm{NaOH}$ aqueous solution and further diluted to $10.0 \mathrm{~g}$ (thus the concentration $=0.2$ wt $\%$ ).

\subsection{Dynamic light scattering (DLS) Study of Thermosensitive Polymethacrylamides in Water}

DLS measurements were performed on a Malvern Zetasizer Nano ZS with a helium-neon laser (wavelength: $633 \mathrm{~nm}$ ) at a scattering angle of $173^{\circ}$. For studying the LCST transitions, the polymer solutions were gradually heated or cooled and at each selected temperature the samples were equilibrated for $1 \mathrm{~min}$ before measurements were taken. The scattering intensity at each temperature was recorded and the onset temperature of the LCST transition from the plot of scattering intensity versus temperature was taken as the cloud point $(\mathrm{CP})[7,8]$. The apparent hydrodynamic diameters $\left(D_{\mathrm{h}}\right)$ reported in this work were the intensity-averaged sizes.

\section{Results and Discussion}

\subsection{Synthesis of Tertiary Amine-Modified L-Alanine-Based Methacrylamide Monomers}

Four L-alanine-based methacrylamide monomers containing different tertiary amine moieties, MAME, MAMP, MAEE, and MAEP (Scheme 1), were prepared in an effort to design thermosensitive water-soluble polymers that are based on natural amino acids and exhibit a LCST transition in the basic $\mathrm{pH}$ range. These monomers were synthesized via a two-step procedure; the first step was the reaction between methacryloyl chloride and $L$-alanine conducted in a basic aqueous solution to give Ma-Ala-OH, which was then activated by $N$-hydroxysuccinimide and dicyclohexylcarbodiimide before reacting with tertiary 
amine-containing primary amines. Compared with 2 -( $N, N$-dialkylamino)ethyl methacrylates, a $L$-alanine motif was inserted as a chiral center between the double bond and the tertiary amine. Four different tertiary amines were used in order to vary the hydrophobicity of the polymers; in addition to 2-dimethylaminoethyl group, we also used 3-dimethylaminopropyl, 2-diethylaminoethyl, and 3-diethylaminopropyl groups considering the two hydrophilic amide groups in the monomers. By doing so, we intended to seek an appropriate hydrophobic/hydrophilic balance to achieve polymers that exhibit thermo-, $\mathrm{pH}-$, as well as $\mathrm{CO}_{2}$-responsive properties while maintaining the chiral property from $L$-alanine.

All four new methacrylamide monomers were thoroughly purified by silica gel column chromatography using methanol/dichloromethane with a volume ratio of $1 / 10$ as eluent and obtained as white solids after drying under high vacuum; the isolation yields were in the range of $40-46 \%$ for the second step reaction. The molecular structures of these monomers were verified by ${ }^{1} \mathrm{H}$ and ${ }^{13} \mathrm{C}$ NMR spectroscopy analysis as well as high resolution mass spectroscopy. As an example, Figure 1A shows the ${ }^{1} \mathrm{H}$ NMR spectrum of MAEE; the expected resonance peaks were all clearly observed, and a quantitative analysis indicated that the integral ratios agreed well with their chemical structures. The HRMS results were also consistent with theoretical values. 

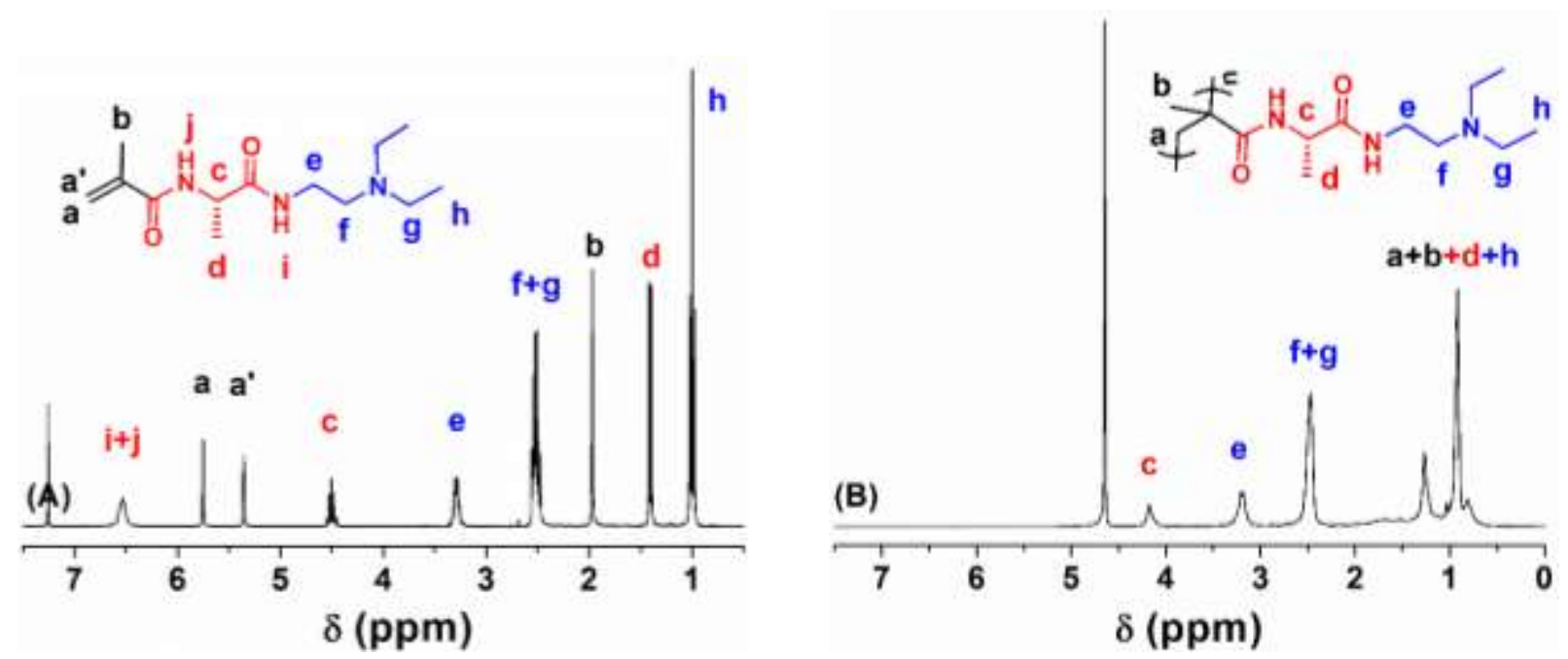

Figure 1. ${ }^{1} \mathrm{H}$ NMR spectra of (A) MAEE monomer in $\mathrm{CDCl}_{3}$ and (B) $\mathrm{PMAEE}_{85}$ (the subscript 85 denotes the degree of polymerization of the polymer) in $\mathrm{D}_{2} \mathrm{O}$.

\subsection{RAFT Polymerization of MAME, MAMP, MAEE, and MAEP}

Considering that these four monomers contained polar amide groups, RAFT polymerization was employed to achieve controlled polymerization of four monomers, MAME, MAMP, MAEE, and MAEP. CDPA and AIBN were used as CTA and initiator, respectively. The polymerizations were carried out in isopropanol at $70{ }^{\circ} \mathrm{C}$ for $24 \mathrm{~h}$, and we found that the best control of the molecular weight distribution as well as monomer conversion was achieved at a CTA-to-initiator molar ratio of 4:1. Using this condition, we first synthesized a series of PMAEE homopolymers with different molecular weights by changing the monomer-to-CTA molar ratios $\left([\mathrm{M}]_{0} /[\mathrm{CTA}]_{0}\right)$. Figure 2 shows the SEC traces of four PMAEE polymers prepared using different $[\mathrm{M}]_{0} /[\mathrm{CTA}]_{0}$ ratios. All obtained polymers showed a monomodal SEC trace with a polydispersity index $(\mathrm{PDI}) \leq 1.43$, which were similar to those of $\operatorname{poly}(($ meth $)$ acrylamide $)$ polymers containing multi-functional polar amides reported in the literatures $[19,35,37]$. Meanwhile, the molecular 
weight from SEC increased monotonically with increasing degree of polymerization (DP), which was calculated from the monomer conversion and the $[\mathrm{M}]_{0} /[\mathrm{CTA}]_{0}$ ratio. The other three monomers were also polymerized by RAFT polymerization under similar conditions. The polymers were purified by precipitation in diethyl ether multiple times to remove residual monomer and other impurities and dried under high vacuum. The polymerization conditions and characterization data of polymers are summarized in Table 1 . Figure $1 \mathrm{~B}$ shows the ${ }^{1} \mathrm{H}$ NMR spectrum of $\mathrm{PMAEE}_{85}$ (the subscript 85 denotes the degree of polymerization of the polymer); all of the characteristic peaks are identified, in good agreement with the corresponding molecular structure.

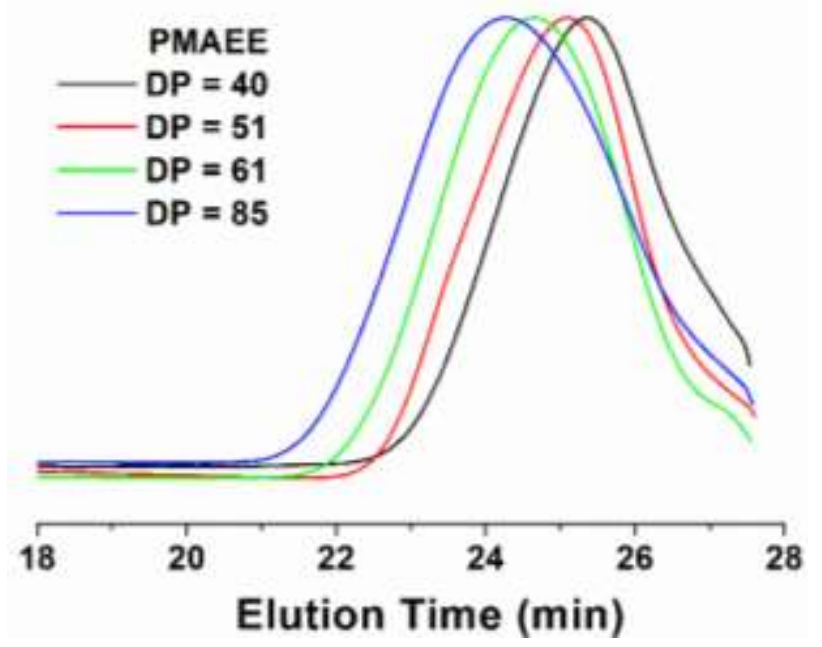

Figure 2. SEC traces of four PMAEE homopolymers prepared by RAFT polymerization in isopropanol at $70^{\circ} \mathrm{C}$ using CDPA as CTA and AIBN as initiator at different $\mathrm{M}_{0} / \mathrm{CTA}_{0}$ ratios. 
Table 1. Characterization Data of PMAME, PMAMP, PMAEE, and PMAEP.

\begin{tabular}{ccccccc}
\hline Sample & {$[\mathrm{M}]_{0}:[\mathrm{CTA}]_{0}$} & $\begin{array}{c}\text { Monomer } \\
\text { Conv. }(\%)\end{array}$ & DP $^{\mathrm{c}}$ & $\begin{array}{c}M_{\mathrm{n}, \text { calc. }} \\
(\mathrm{kDa})\end{array}$ & $\begin{array}{c}M_{\mathrm{n}, \text { SEC. }} \\
(\mathrm{kDa})\end{array}$ & PDI $^{\mathrm{e}}$ \\
\hline PMAEE $_{85}{ }^{\mathrm{a}}$ & $125: 1$ & 68 & 85 & 22.1 & 39.5 & 1.43 \\
PMAEE $_{61}$ & $85: 1$ & 72 & 61 & 16.0 & 37.3 & 1.36 \\
PMAEE $_{51}$ & $65: 1$ & 78 & 51 & 13.4 & 33.0 & 1.37 \\
PMAEE $_{40}$ & $50: 1$ & 80 & 40 & 10.6 & 27.3 & 1.31 \\
\hline PMAME $_{70}$ & $100: 1$ & 70 & 70 & 16.3 & 34.5 & 1.40 \\
PMAMP $_{80}$ & $100: 1$ & 80 & 80 & 19.7 & 38.7 & 1.36 \\
PMAEP $_{84}$ & $100: 1$ & 84 & 84 & 23.0 & 43.2 & 1.35 \\
\hline
\end{tabular}

${ }^{\mathrm{a}}$ The polymer sample was named after the monomer with the degree of polymerization (DP) appended as a subscript; ${ }^{b}$ monomer conversion was determined by ${ }^{1} \mathrm{H}$ NMR spectroscopy analysis; ${ }^{\mathrm{c}} \mathrm{DP}$ was calculated by multiplying the monomer conversion and the monomer-to-CTA molar ratio; ${ }^{\mathrm{d}} M_{\mathrm{n} \text {,calc }}$ was the molecular weight calculated by using the DP and monomer molar mass; ${ }^{\mathrm{e}}$ molecular weight $\left(M_{\mathrm{n}, \mathrm{SEC}}\right)$ and polydispersity index (PDI) obtained from SEC analysis against polystyrene standards.

\subsection{Circular Dichroism Spectroscopy Study of PMAEE}

Circular dichroism (CD) spectroscopy was conducted to assess the optical activity of the PMAEE $_{85}$ in pure water at room temperature (Figure 3). MMAEE $_{85}$ exhibited a negative CD signal at $197 \mathrm{~nm}$ and a positive CD signal at $227 \mathrm{~nm}$ with an intensity of about -39000 and 2500 deg. $\mathrm{cm}^{2} \cdot \mathrm{dmol}{ }^{-1}$, respectively. This result was similar to those of poly(meth)acrylamides containing natural amino acids in their side chains such as poly(A-Pro-OMe) and poly(MA-Ala-OMe) $[17,26]$. Typically, the peak at $\sim 200 \mathrm{~nm}$ was attributed to the $\pi_{2} \rightarrow \pi^{*}$ transition or the $n \rightarrow \sigma$ transition of the amide group, while the signals near 207 and $230 \mathrm{~nm}$ were attributed to the $n \rightarrow \pi^{*}$ transition of the carboxyl chromophore and $\pi_{1} \rightarrow \pi^{*}$ transition of the amide chromophore, respectively [42]. Compared with the reported multi-responsive tertiary 
amine-based thermosensitive polymers, the optical activity from amino acids might offer more potential applications $[19,22,23,26]$.

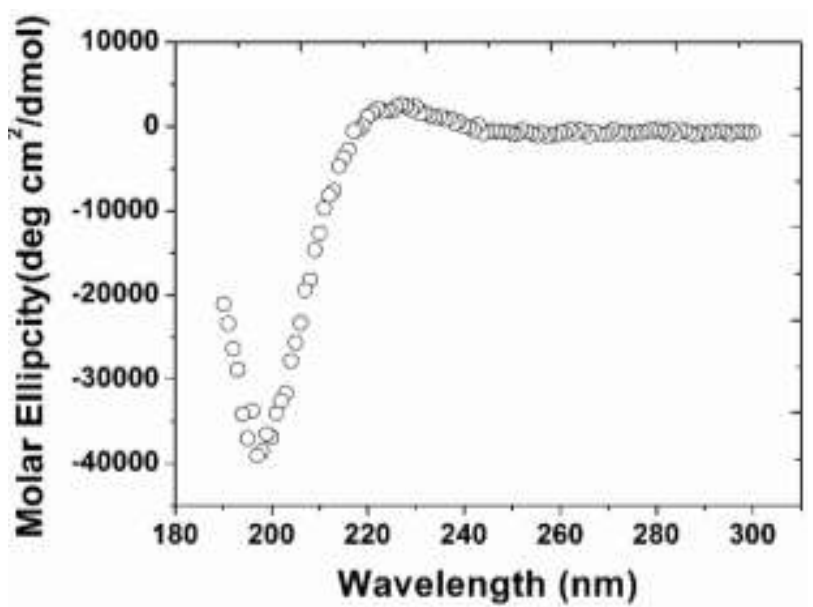

Figure 3. Circular dichroism (CD) spectrum of $\mathrm{PMAEE}_{85}$ in pure water at room temperature.

\subsection{Thermoresponsive Properties of Tertiary Amine-Modified L-Alanine-Based}

Polymethacrylamide Homopolymers in Water

All of four tertiary amine-modified $L$-analine-based polymethacrylamide homopolymers were found to be soluble in pure water to give solutions with basic $\mathrm{pH}$ values, and displayed LCST-type thermosensitive properties under certain conditions in water depending on their chemical structures. For example, PMAEE $_{85}$ dissolved in pure water, forming a clear solution with a $\mathrm{pH}$ of around 10.0 at a concentration of $0.2 \mathrm{wt} \%$. Simply heating the solution caused a transition from clear to cloudy, and upon cooling the cloudy solution returned to clear, suggesting a typical reversible LCST transition. To measure the cloud point of $\mathrm{PMAEE}_{85}$ in water at a concentration of $0.2 \mathrm{wt} \%$, dynamic light scattering (DLS) was employed. The solution was gradually heated, and at each temperature the sample was equilibrated for $1 \mathrm{~min}$ before the 
scattering intensity and the apparent hydrodynamic size $\left(D_{\mathrm{h}}\right)$ were measured. Figure 4 shows the plot of scattering intensity versus temperature for this sample. At temperatures below $37{ }^{\circ} \mathrm{C}$, the solution was completely clear as shown in the photo included in Figure 4, giving very low scattering intensity. When the temperature was above $38{ }^{\circ} \mathrm{C}$, the scattering increased sharply, and the clear solution rapidly turned turbid (Figure 4). The onset temperature of the transition, $38^{\circ} \mathrm{C}$, was taken as cloud point in the present work.[7, 8] A small hysteresis, $1^{\circ} \mathrm{C}$, was observed in the cooling process, with the transition occurring at $37^{\circ} \mathrm{C}$. DLS was also used to monitor in situ the $D_{\mathrm{h}}$ of $\mathrm{PMAEE}_{85}$ in $\mathrm{H}_{2} \mathrm{O}$ upon heating. Below its cloud point $\left(38^{\circ} \mathrm{C}\right)$, the $D_{\mathrm{h}}$ was less than $10 \mathrm{~nm}$, indicating that the polymer was molecularly dissolved in water. When the temperature reached $40{ }^{\circ} \mathrm{C}, 2{ }^{\circ} \mathrm{C}$ above its cloud point, the $D_{\mathrm{h}}$ jumped to $540 \mathrm{~nm}$. After the solution was kept at this temperature for $2 \mathrm{~h}$, the polymer settled at the bottom of the vial as a white precipitate, indicating strong hydrophobic interactions among polymer molecules.

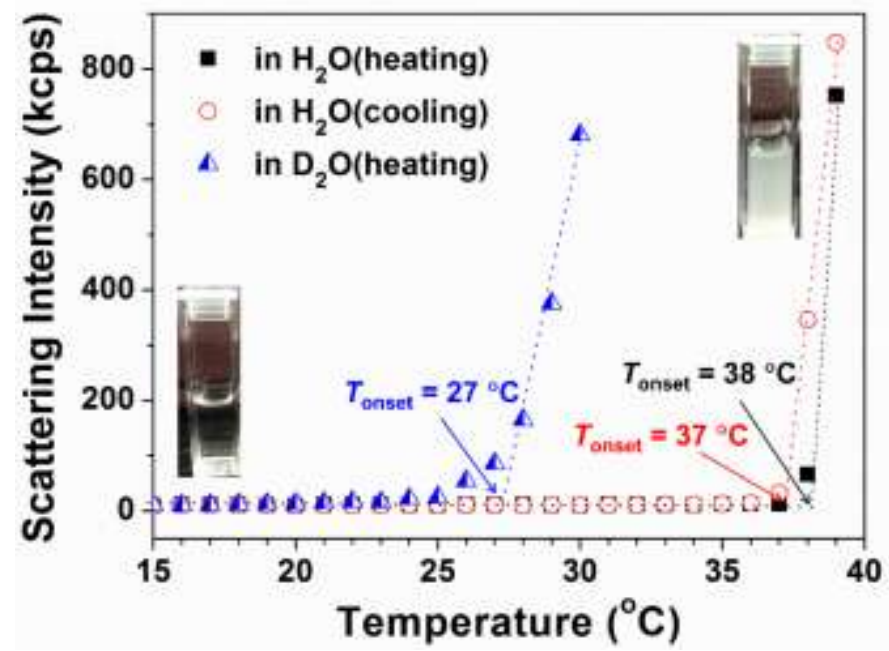

Figure 4. Scatter intensity of a $0.2 \mathrm{wt} \%$ aqueous solution of $\mathrm{PMAEE}_{85}$ as a function of temperature obtained from dynamic light scattering experiments. 
Isotopic solvent is usually applied to investigate the LCST transition of thermosensitive polymers in water. For example, the cloud point of PNIPAM in $\mathrm{D}_{2} \mathrm{O}$ was $\sim 2{ }^{\circ} \mathrm{C}$ higher than that in $\mathrm{H}_{2} \mathrm{O}$, because the hydrogen bond between the amide group and $\mathrm{D}_{2} \mathrm{O}$ is $\sim 5 \%$ stronger than that with $\mathrm{H}_{2} \mathrm{O}$ [43]. Differently, for poly( $N$-(2-methacryloyloxyethyl)pyrrolidone), the cloud point was found to be $\sim 9{ }^{\circ} \mathrm{C}$ lower in $\mathrm{D}_{2} \mathrm{O}$ than in $\mathrm{H}_{2} \mathrm{O}$ because of the hydrophobic association [8]. Therefore, we made a $0.2 \mathrm{wt} \%$ solution of PMAEE 85 in $\mathrm{D}_{2} \mathrm{O}$. As shown in Figure 4, the cloud point of $\mathrm{PMAEE}_{85}$ in $\mathrm{D}_{2} \mathrm{O}$ was $11.0{ }^{\circ} \mathrm{C}$ lower than that in $\mathrm{H}_{2} \mathrm{O}$ in the heating processes, similar to the observation for $\operatorname{poly}(N-(2$-methacryloyloxyethyl)pyrrolidone). This indicated that the thermosensitivity of PMAEE was a result of hydrophobic association.

We also used variable temperature ${ }^{1} \mathrm{H}$ NMR spectroscopy to study the LCST transition of $\mathrm{PMAEE}_{55}$ in $\mathrm{D}_{2} \mathrm{O}$ by monitoring the peaks of characteristic protons in $\mathrm{PMAEE}_{85}$ with increasing temperatures (Figure 5A). At each selected temperature the sample was equilibrated for $15 \mathrm{~min}$ before measurements were taken. PMAEE was found to be well dissolved in $\mathrm{D}_{2} \mathrm{O}$ at lower temperatures $\left(<28{ }^{\circ} \mathrm{C}\right)$, evidenced by the sharp peaks in the spectrum. Upon heating to $32{ }^{\circ} \mathrm{C}$ from $28{ }^{\circ} \mathrm{C}$, the signals became lower and broadened noticeably, indicating the dehydration of PMAEE $_{85}$ in $\mathrm{D}_{2} \mathrm{O}$. The plots of integrals of various characteristic protons, normalized against the residual solvent peak, versus temperature showed a clear transition with the onset temperature at $28{ }^{\circ} \mathrm{C}$ in $\mathrm{D}_{2} \mathrm{O}$ (Figure 5B), in good agreement with the DLS study, which showed that the onset temperature occurred at $27{ }^{\circ} \mathrm{C}$ (Figure 4). Interestingly, the plots for different protons overlapped, indicating that the dehydration of hydrophobic and hydrophilic groups occurred simultaneously. 
This suggests strong self-association of the polymer molecules above the LCST transition, consistent with the observation that the polymer settled at the bottom of the vial after the solution was kept at a temperature above the cloud point for a couple of hours.
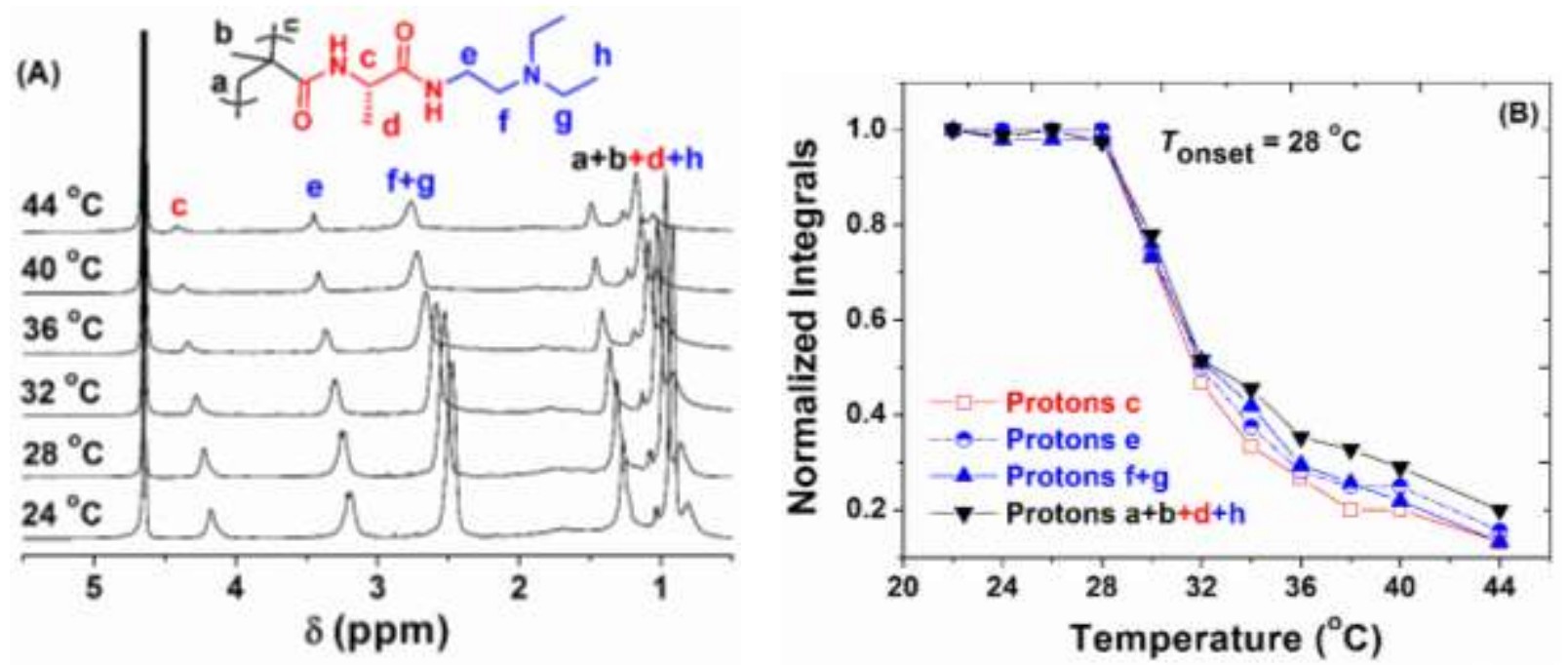

Figure 5. (A) ${ }^{1} \mathrm{H}$ NMR spectra of $\mathrm{PMAEE}_{85}$ in $\mathrm{D}_{2} \mathrm{O}$ with a concentration of $2.0 \mathrm{mg} / \mathrm{mL}$ at various temperatures using the solvent residual proton peak as internal standard; (B) the integrals of characteristic protons of PMAEE $_{85}$ normalized against that of the solvent residual proton as a function of temperature.

We then studied how the solution $\mathrm{pH}$ affected the LCST transition of PMAEE 85 in $\mathrm{H}_{2} \mathrm{O}$. The $\mathrm{pH}$ of the polymer solution was adjusted to desired values by adding $\mathrm{NaOH}$ or $\mathrm{HCl}$ aqueous solution, and the sample was studied by DLS as for the solution of $\mathrm{PMAEE}_{85}$ in pure water at a concentration of $0.2 \mathrm{wt} \%$. Figure $6 \mathrm{~A}$ shows the scattering intensity of $0.2 \mathrm{wt} \% \mathrm{PMAEE}_{85}$ aqueous solutions with various $\mathrm{pH}$ values versus temperature. At $\mathrm{pH}$ of 8.0 or lower, no LCST transition was detected in the temperature range of $\sim 0$ to $100{ }^{\circ} \mathrm{C}$. At $\mathrm{pH}$ of 9.0 or higher, a clouding transition was observed as indicated by the sharp increase in scattering intensity shown in Figure 6. With the increase of the $\mathrm{pH}$ from 9.0 to 9.5, 10.0, 11.0 and 13.0, the cloud point 
decreased from 66.0 to $44.0,38.0,32.0$ and $27.0^{\circ} \mathrm{C}$, respectively (Figure 6B). Further increasing $\mathrm{pH}$ to 14.0 , the clear solution turned cloudy, and polymer precipitated at the bottom of the vial. The precipitate remained insoluble even after keeping the vial in an ice/water bath $\left(\sim 0{ }^{\circ} \mathrm{C}\right)$ for 8 h. However, after adding $\mathrm{HCl}$ solution to adjust the $\mathrm{pH}$ back to 13.0 at ambient temperature, the polymer dissolved immediately, indicating a sharp $\mathrm{pH}$-sensitivity. These results were similar to the behavior of PDMAEMA in water, which had a cloud point of $\sim 50{ }^{\circ} \mathrm{C}$ at $\mathrm{pH}=8$ and $\sim 36^{\circ} \mathrm{C}$ at $\mathrm{pH}=10[32,38]$. The reported $\mathrm{p} K_{\mathrm{a}}$ values of poly(2-(N,N-dimethylamino)ethyl methacrylate $)$ and poly(2-(N,N-diethylaminoethyl methacrylate) in water were both around $7.4[31,40]$. Thus, with decreasing $\mathrm{pH}$, more tertiary amine groups were protonated, which increased the hydrophilicity of polymer chains. Consequently, a higher temperature was required to compensate for the enhanced hydrophilicity from charged $\mathrm{NR}_{3}{ }^{+}$groups to reach the LCST transition, resulting in a higher cloud point at a lower $\mathrm{pH}$ value.
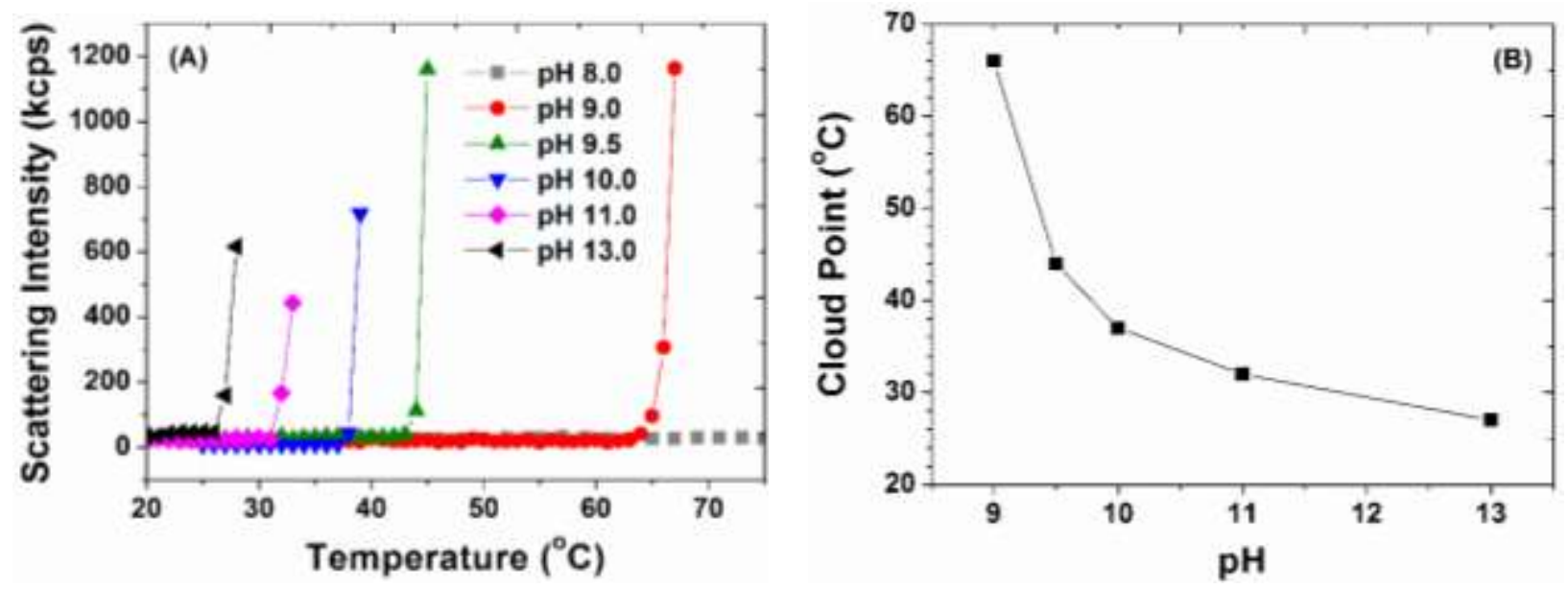

Figure 6. (A) Plots of scattering intensity versus temperature obtained from a dynamic light scattering study of $0.2 \mathrm{wt} \%$ aqueous solutions of $\mathrm{PMAEE}_{85}$ at various $\mathrm{pH}$ values in heating ramp experiments; (B) $\mathrm{pH}$ dependence of cloud point of $\mathrm{PMAEE}_{85}$ in aqueous solution at a concentration of $0.2 \mathrm{wt} \%$, determined from (A) plots of scattering intensity versus temperature. 
The other three polymethacrylamides, PMAME, PMAMP, and PMAEP, also exhibited LCST-type thermosensitive properties in water but in rather narrower $\mathrm{pH}$ ranges compared with PMAEE. For comparison, the results for $0.2 \mathrm{wt} \%$ aqueous solutions of these four polymers are summarized in Table 2. As discussed earlier, $\mathrm{PMAEE}_{85}$ showed thermosensitive properties in the $\mathrm{pH}$ range of 9.0 to 13.0 and its cloud point decreased with increasing $\mathrm{pH}$ (Figure 6). Differently, PMAME $_{70}$, which had a DP of 70 similar to $\mathrm{PMAEE}_{85}$, only exhibited a cloud point at $27{ }^{\circ} \mathrm{C}$ at $\mathrm{pH}=14.0$; below $\mathrm{pH}=14.0$, the solution stayed clear even when the temperature increased to nearly $100{ }^{\circ} \mathrm{C}$. Apparently, replacing two ethyl groups of the tertiary amine moiety with two methyl groups greatly increased the hydrophilicity of the polymer, and only at such a high $\mathrm{pH}$ did PMAME PM $_{70}$ show a LCST behavior in water. Inserting one additional methylene group between the amide linkage and the dimethylamino moiety of PMAME, i.e., PMAMP, resulted in thermoresponsive properties in a slightly wider $\mathrm{pH}$ range, with a cloud point of $69^{\circ} \mathrm{C}$ at $\mathrm{pH}=$ 13.0 and a cloud point of $26^{\circ} \mathrm{C}$ at $\mathrm{pH}=14.0$. This is consistent with what was expected as a spacer of three methylenes is more hydrophobic than the ethylene linkage.

PMAEP, the polymethacrylamide that had the most hydrophobic alkyl groups in the molecular structure among four polymers, showed cloud points at $\mathrm{pH}$ values of 11.0 (cloud point: $26{ }^{\circ} \mathrm{C}$ ) and 12.0 (cloud point: $25^{\circ} \mathrm{C}$ ) but precipitated at $\mathrm{pH} \geq 13.0$ at room temperature. The polymer remained settled even after putting the vial into an ice/water bath for $8 \mathrm{~h}$, but became clear immediately after the addition of $\mathrm{HCl}$ solution. From DLS study, assemblies with apparent hydrodynamic sizes of $\sim 20 \mathrm{~nm}$ were observed in PMAEP $_{84}$ aqueous solutions with $\mathrm{pH}$ of 11.0 
and 12.0 at temperatures below the cloud points, indicating strong inter- and intramolecular association. Note that the apparent hydrodynamic sizes of other three thermosensitive polymers studied in this work below their respective LCSTs were $<10 \mathrm{~nm}$. Unexpectedly, no obvious LCST transition was found at $\mathrm{pH}=10.0$ and below. Nevertheless, one can see a clear trend of the solution behavior of four polymers at $\mathrm{pH}=13.0$ with increasing hydrophobicity of polymer molecular structures from PMAME to PMAMP, PMAEE, and PMAEP; while PMAME 70 was completely soluble even at $\sim 100{ }^{\circ} \mathrm{C}, \mathrm{PMAMP}_{80}$ and $\mathrm{PMAEE}_{85}$ exhibited LCST transitions at 69 and $27{ }^{\circ} \mathrm{C}$, respectively, and $\mathrm{PMAEP}_{84}$ was insoluble. Similar trends can also be seen from the solution behaviors of these four $L$-alanine-derived polymethacrylamides at $\mathrm{pH}=11.0$ and 12.0. These results were consistent with the reports in the literature for other thermoresponsive polymers. For example, Endo group found that poly( $N$-acryloyl- $L$-proline methyl ester) had a cloud point of $15{ }^{\circ} \mathrm{C}$ [16], while poly( $N$-acryloyl-4-trans-hydroxy-L-proline methyl ester), containing an additional hydroxyl group, had a cloud point of $49.5{ }^{\circ} \mathrm{C}$. Further changing the $-\mathrm{COOCH}_{3}$ to $-\mathrm{COOH}$ gave a fully water soluble polymer [18]. For PNIPAM analogues, the hydrophobicity of $\mathrm{N}$-substituents determined the solution properties of the corresponding polymers [44]. For example, poly $(N, N$-dimethylacrylamide) was totally soluble in water, while poly $\left(N, N\right.$-diethylacrylamide) displayed a cloud point at $32{ }^{\circ} \mathrm{C}$ and poly $(N$-butylacrylamide $)$ was insoluble in pure water. Apparently, a slight variation in polymer molecular structure could change the responsive property dramatically. 
Table 2. Cloud points of PMAME, PMAMP, PMAEE, and PMAEP.

\begin{tabular}{ccccccc}
\hline Sample & $\mathrm{pH}=9.0$ & $\mathrm{pH}=10.0$ & $\mathrm{pH}=11.0$ & $\mathrm{pH}=12.0$ & $\mathrm{pH}=13.0$ & $\mathrm{pH}=14.0$ \\
\hline PMAME $_{70}$ & $\mathrm{~S}^{\mathrm{a}}$ & $\mathrm{S}$ & $\mathrm{S}$ & $\mathrm{S}$ & $\mathrm{S}$ & $27{ }^{\circ} \mathrm{C}$ \\
PMAMP $_{80}$ & $\mathrm{~S}$ & $\mathrm{~S}$ & $\mathrm{~S}$ & $\mathrm{~S}$ & $69^{\circ} \mathrm{C}$ & $26{ }^{\circ} \mathrm{C}$ \\
PMAEE $_{85}$ & $66^{\circ} \mathrm{C}$ & $38^{\circ} \mathrm{C}$ & $32^{\circ} \mathrm{C}$ & $31^{\circ} \mathrm{C}$ & $27{ }^{\circ} \mathrm{C}$ & $\mathrm{I}^{\mathrm{b}}$ \\
PMAEP $_{84}$ & $\mathrm{~S}$ & $\mathrm{~S}$ & $26{ }^{\circ} \mathrm{C}$ & $25^{\circ} \mathrm{C}$ & $\mathrm{I}$ & $\mathrm{I}$ \\
\hline
\end{tabular}

${ }^{\mathrm{a}} \mathrm{S}$ indicated that the polymer was soluble in water up to $100{ }^{\circ} \mathrm{C} ;{ }^{\mathrm{b}} \mathrm{I}$ indicated that the polymer was insoluble in water even at $0{ }^{\circ} \mathrm{C}$; ${ }^{\mathrm{c}}$ assemblies with apparent hydrodynamic diameter of around $20 \mathrm{~nm}$ were observed at temperatures below the cloud point. The concentration for all samples was $2.0 \mathrm{mg} / \mathrm{mL}$.

\subsection{Effects of Various Factors on Cloud Point of PMAEE in Water}

Since PMAEE showed a LCST-type thermosensitivity with a $\mathrm{pH}$-dependent cloud point over a wide $\mathrm{pH}$ range from 9.0 - 13.0, we further studied the effects of various factors, including polymer molecular weight, polymer concentration, addition of $\mathrm{NaCl}$, and end group, on the thermosensitive property of this polymethacrylamide.

The PMEE homopolymer with the lowest DP in Table $1\left(\mathrm{PMAEE}_{40}\right)$ was selected for studying the dependence of cloud point on polymer concentration at $\mathrm{pH}=10.0$. Note that this polymer was synthesized by RAFT polymerization using CDPA as CTA and thus had end groups of $n$-dodecyl and $-\mathrm{COOH}$. The cloud points of aqueous solutions of this polymer with different concentrations at $\mathrm{pH}=10.0$ were measured by DLS as for $\mathrm{PMAEE}_{40}$ in pure water, and the $\mathrm{pH}$ was kept at $\mathrm{pH}=10.0$ by using $\mathrm{NaOH}$ solution. We found that the cloud point increased from 37.0 to $42.0^{\circ} \mathrm{C}$ when the concentration decreased from 2.0 to $0.2 \mathrm{mg} / \mathrm{mL}$ (Figure $7 \mathrm{~A}$ ), consistent with what was expected and the observations for other thermosensitive water-soluble polymers 
$[45,46]$. Besides the concentration, the cloud point of a thermosensitive polymer in water could also be affected by its molecular weight at the same polymer concentration. The cloud points of PMAEE homopolymers with DPs of 40, 51, 61, and 85 (Table 1) in $\mathrm{pH}=10.0$ aqueous solutions at a $0.2 \mathrm{wt} \%$ polymer concentration were found to be very close to each other (Figure $7 \mathrm{~B}$ ), being $38,39,38$, and $38^{\circ} \mathrm{C}$, respectively, indicating that the DP in this range had little effect on cloud point. Sodium chloride is widely used in biological systems, and adding $\mathrm{NaCl}$ usually results in a salting out effect owing to the high charge density on cation $\mathrm{Na}^{+}$. We found that adding $\mathrm{NaCl}$ suppressed the cloud point of $\mathrm{PMAEE}_{40}$ in water, and interestingly, the cloud point decreased linearly with the concentration of $\mathrm{NaCl}$, from $38.0^{\circ} \mathrm{C}$ without $\mathrm{NaCl}$ to $27.0^{\circ} \mathrm{C}$ with $[\mathrm{NaCl}]=1.0$ M, as shown in Figure 7C. The suppression of cloud point has been attributed to the disruption of ordered water structure around the hydrophobic groups [47].

The end groups of polymer chains are known to influence the cloud point of a thermosensitive polymer in water. Hydrophilic end groups tend to increase the cloud point because of the enhanced hydrophilicity of the whole polymer chains, while hydrophobic end groups tend to decrease cloud point.[27, 45, 48] The PMAEE homopolymers studied so far were made by RAFT polymerization using CDPA as CTA, which yielded a hydrophobic long alkyl group $\left(n-\mathrm{C}_{12} \mathrm{H}_{25}\right)$ and a hydrophilic $-\mathrm{COOH}$ group. The effects of two end groups counteract each other. To investigate the effect of end group, three PMAEE polymers with similar DPs $(\sim 40)$ were prepared by RAFT using three different CTAs (Schemes 1 and S1), yielding polymers with different terminals. The polymers were named after the corresponding CTA and the 
characterization data are summarized in Table S1. PMAEE $40-$ CDPA had one hydrophobic dodecyl terminal and a hydrophilic carboxyl acid group originated from CDPA (same as the $\mathrm{PMAEE}_{40}$ in Table 1), and PMAEE $38-\mathrm{CBPA}$ had an $n$-butyl group and a carboxyl acid terminal, whereas PMAEE ${ }_{37}-\mathrm{CBTB}$ had two hydrophobic alkyl ends: $n$-butyl and methyl. As revealed by the plots of scattering intensity versus temperature in Figure 7D for the three polymers at the same concentration of $0.2 \mathrm{wt} \%$ in water, $\mathrm{PMAEE}_{37}-\mathrm{CBTB}$ with two hydrophobic alkyl groups had the lowest $\mathrm{CP}$ of $34.0{ }^{\circ} \mathrm{C}$, while $\mathrm{PMAEE}_{38}-\mathrm{CBPA}$ with an $n$-butyl at one end and $-\mathrm{COOH}$ at another exhibited the highest $\mathrm{CP}$ of $40.0{ }^{\circ} \mathrm{C}$. The cloud point of $\mathrm{PMEE}_{40}-\mathrm{CDPA}$ was $38.0{ }^{\circ} \mathrm{C}$, which was in between those of the other two polymers due to the presence of a long dodecyl group and a hydrophilic $\mathrm{COOH}$. These results were consistent with the observations for other thermosensitive water-soluble polymers [27, 45, 46], demonstrating that modifying the chain end groups is a viable means for tuning the cloud point of a thermosensitive polymer in water.
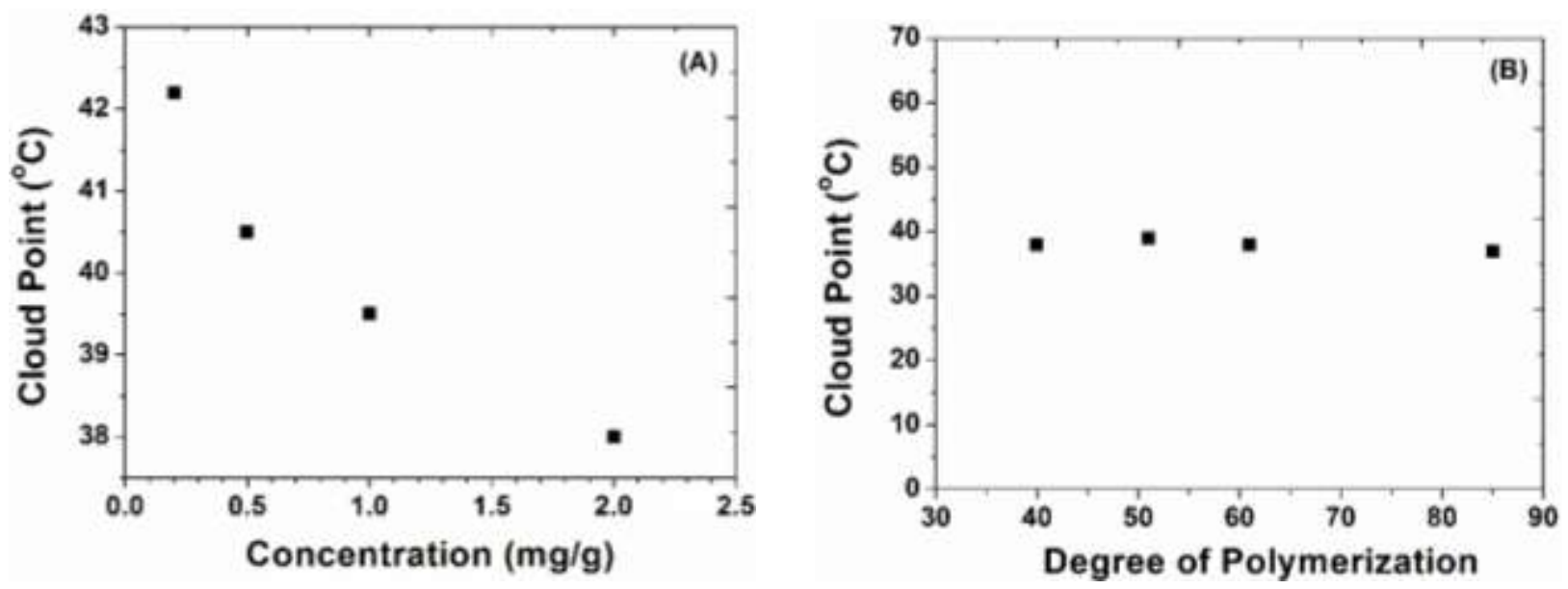

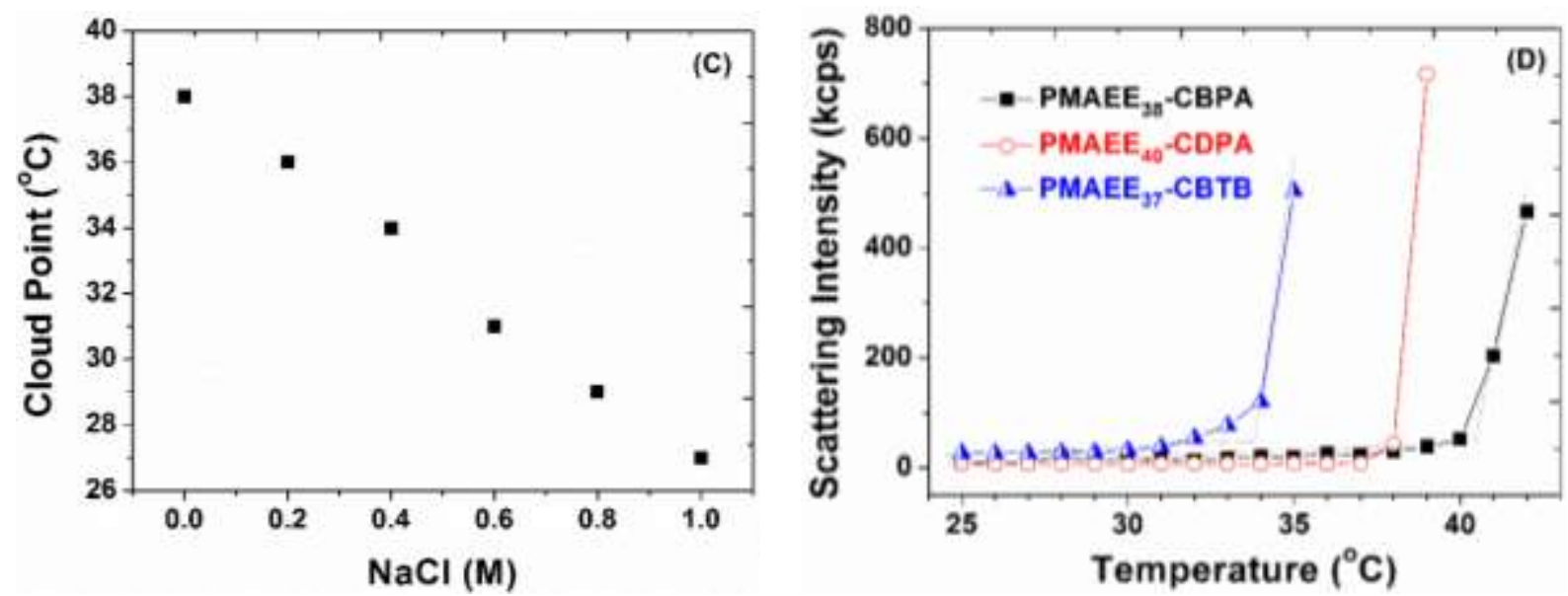

Figure 7. (a) Plot of cloud point of $\mathrm{PMAEE}_{40}$ in water at $\mathrm{pH}=10.0$ versus polymer concentration; (b) plot of cloud point of PMAEE in water at $\mathrm{pH}=10.0$ versus polymer degree of polymerization (DP) at a concentration of $0.2 \mathrm{wt} \%$; (c) effect of $\mathrm{NaCl}$ concentration on cloud point of $0.2 \mathrm{wt} \% \mathrm{PMAEE}_{40}$ solution at $\mathrm{pH}=10$; and (d) cloud points of PMAEE homopolymers with different terminals in $\mathrm{pH}=10$ water at a concentration of $0.2 \mathrm{wt} \%$.

\section{6. $\mathrm{CO}_{2}$-Responsive Property of PMAEE in Water}

The introduction of tertiary amine moieties into a polymer endows it with a $\mathrm{CO}_{2}$-responsive property as demonstrated by many researchers with tertiary amine-containing polymers [39]. $\mathrm{CO}_{2}$ gas is a unique $\mathrm{pH}$ stimulus which upon dissolution in water forms carbonic acid, a weak acid that undergoes ionization. It has been reported that tertiary amines can be protonated in water by $\mathrm{CO}_{2}$ gas, producing an ammonium bicarbonate. The dissolved $\mathrm{CO}_{2}$ can be easily removed by bubbling the aqueous solution with an inert gas such as $\mathrm{N}_{2}$ or Ar. We showed in Figure 6 that the cloud point of PMAEE in water varied significantly with $\mathrm{pH}$ at $\mathrm{pH}=\sim 10.0$, prompting us to demonstrate the $\mathrm{CO}_{2}$-responsive property of PMAEE at this $\mathrm{pH}$. A $0.2 \mathrm{wt} \%$ aqueous solution of $\mathrm{PMAEE}_{85}$ with $\mathrm{pH}$ of 10.0 was made, and the cloud point was found to be 38 
${ }^{\circ} \mathrm{C}$ by DLS. At $48{ }^{\circ} \mathrm{C}$ the solution was turbid and the scattering intensity was high (Figure 8 ). After bubbling $\mathrm{CO}_{2}$ through this solution, the sample turned clear and the scattering intensity decreased from $134 \mathrm{kcps}$ to $\sim 18 \mathrm{kcps}$, accompanied by the decrease of $\mathrm{pH}$ from 10.0 to 5.9. No LCST transition was detected even when the temperature was raised to nearly $100{ }^{\circ} \mathrm{C}$. Subsequent purging of the solution with $\mathrm{N}_{2}$ at $48{ }^{\circ} \mathrm{C}$ for 60 min to remove $\mathrm{CO}_{2}$ caused it to turn cloudy, and the scattering intensity showed a dramatic jump to a level that was only slightly lower than that before bubbling with $\mathrm{CO}_{2}$. The $\mathrm{pH}$ increased from 5.9 to $\sim 9.5$. DLS study revealed that the cloud point after bubbling $\mathrm{N}_{2}$ was $\sim 43.0{ }^{\circ} \mathrm{C}$, slightly higher than that of the fresh PMAEE $_{85}$ aqueous solution $\left(38.0{ }^{\circ} \mathrm{C}\right)$ even after bubbling with $\mathrm{N}_{2}$ for $8 \mathrm{~h}$. A similar difference was also observed for diethyl-related polymer solutions after bubbling with $\mathrm{CO}_{2}$ and $\mathrm{N}_{2}[36,34]$, which was ascribed to the strong interaction between $\mathrm{CO}_{2}$ and the diethylamino group $[39,48]$. The cloudy-clear-cloudy transition of the 0.2 wt\% PMAEE $_{85}$ solution by bubbling alternately $\mathrm{CO}_{2}$ and $\mathrm{N}_{2}$ can be repeated multiple times with little or no hysteresis as shown in Figure 8, demonstrating the robust $\mathrm{CO}_{2}$-responsive property of PMAEE.

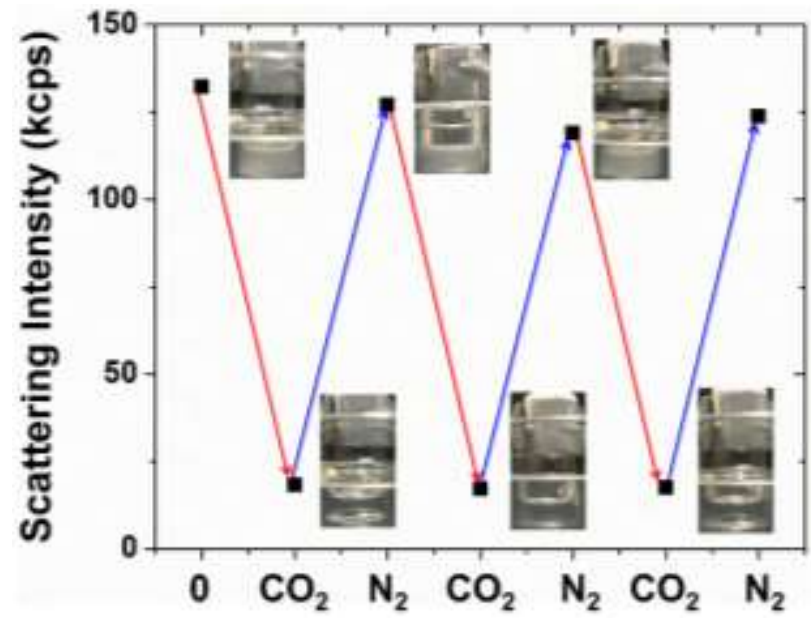


Figure 8. Scatter intensities obtained from dynamic light scattering measurements and digital photos of a $0.2 \mathrm{wt} \%$ aqueous solution of $\mathrm{PMAEE}_{85}$ at $48{ }^{\circ} \mathrm{C}$ after alternate bubbling with $\mathrm{CO}_{2}$ and $\mathrm{N}_{2}$.

\section{Conclusion}

Four different tertiary amine-modified $L$-alanine-based polymethacrylamides were synthesized by RAFT polymerization. While all four polymers exhibited a LCST behavior in water under certain conditions, only PMAEE was found to show thermosensitive properties over a wide $\mathrm{pH}$ range from 9.0 to 13.0 ; the cloud point decreased with increasing solution $\mathrm{pH}$, consistent with the expected for tertiary amine-containing polymers. A more in-depth study of the thermosensitive property of PMAEE revealed that the cloud point of this polymer in water decreased with increasing polymer concentration, adding $\mathrm{NaCl}$, and introducing hydrophobic end groups, but varied little with the polymer molecular weight. We further demonstrated that

PMAEE exhibited a $\mathrm{CO}_{2}$-responsive property by bubbling a $0.2 \mathrm{wt} \%$ polymer solution alternately with $\mathrm{CO}_{2}$ and $\mathrm{N}_{2}$ at $48{ }^{\circ} \mathrm{C}$. It should be emphasized here that the triply responsive property of PMAEE arose from the homopolymer of a single monomer derived from a tertiary amine-modified natural amino acid with a chiral center. These natural amino acid-based multi-responsive polymers could be used to make intelligent materials for, e.g., biomedical applications.

Acknowledgments. This work was supported by the National Science Foundation (NSF DMR-1607076), the National Natural Science Foundation of China (21464001), and Science 
Foundation of Ningxia Colleges (NGY20140150). C.L. was supported by China Scholarship Council (CSC) and the "2014 Western Light" Program for Scholars in Western China.

Appendix A. Supplementary Data. Supplementary data related to this article can be found at http://dx.doi. XXXX.

\section{References}

[1] D. Roy, W.L.A. Brooks, B.S. Sumerlin, Chem. Soc. Rev. 42 (2013), pp. 7214-7243.

[2] I. Dimitrov, B. Trzebicka, A.H.E. Müller, A. Dworak, C.B. Tsvetanov, Prog. Polym. Sci. 32 (2007), pp. 1275-1343.

[3] J. Hu, G. Zhang, Z. Ge, S. Liu, Prog. Polym. Sci. 39 (2013), pp. 1096-1143.

[4] H.G. Schild, Prog. Polym. Sci. 17 (1992), pp. 163-249.

[5] X. Jiang, B. Wang, C.Y. Li, B. Zhao, J. Polym. Sci., Part A: Polym. Chem. 47 (2009), pp. 2853-2870.

[6] F. Hua, X. Jiang, D. Li, B. Zhao, J. Polym. Sci., Part A: Polym. Chem. 44 (2006), pp. 2454-2467.

[7] J. Deng, Y. Shi, W. Jiang, Y. Peng, L. Lu, Y. Cai, Macromolecules 41 (2008), pp. 3007-3014.

[8] J. Sun, Y. Peng, Y. Chen, Y. Liu, J. Deng, L. Lu, Y. Cai, Macromolecules 43 (2010), pp. 4041-4049.

[9] H. Lai, G. Chen, P. Wu, Z. Li, Soft Matter 8 (2012), pp. 2662-2670.

[10] C.M. Chopko, E.L. Lowden, A.C. Engler, L.G. Griffith, P.T. Hammond, ACS Macro Lett. 1 (2012), pp. 727-731.

[11] S. Zhang, C. Chen, Z. Li, Chin. J. Polym. Sci. 31 (2013), pp. 201-210.

[12] Y. Cheng, C. He, C. Xiao, J. Ding, X. Zhuang, X. Chen, Poly. Chem. 2 (2011), pp. 2627-2634. 
[13] Yoichi Tachibana, Motoichi Kurisawa, Hiroshi Uyama, Toyoji Kakuchic, S. Kobayashi, Chem. Commun. 1(2003), pp. 106-107.

[14] X. Huang, F. Du, J. Cheng, Y. Dong, D. Liang, S. Ji, S.-S. Lin, Z. Li, Macromolecules 42 (2009), pp. 783-790.

[15] T.G. O'Lenick, X. Jiang, B. Zhao, Langmuir 26 (2010), pp. 8787-8796.

[16] H. Mori, H. Iwaya, A. Nagai, T. Endo, Chem. Commun. 38(2005), pp. 4872-4874.

[17] H. Mori, H. Iwaya, T. Endo, Macromol. Chem. Phys. 208 (2007), pp. 1908-1918.

[18] H. Mori, I. Kato, M. Matsuyama, T. Endo, Macromolecules 41 (2008), pp. 5604-5615.

[19] K. Shoji, M. Nakayama, T. Koseki, K. Nakabayashi, H. Mori, Polymer 97 (2016), pp. 20-30.

[20] B.S. Lokitz, A.J. Convertine, R.G. Ezell, A. Heidenreich, Y. Li, C.L. McCormick, Macromolecules 39 (2006), pp. 8594-8602.

[21] B.S. Lokitz, A.W. York, J.E. Stempka, N.D. Treat, Y. Li, W.L. Jarrett, C.L. McCormick, Macromolecules 40 (2007), pp. 6473-6480.

[22] J. Skey, C.F. Hansell, R.K. O'Reilly, Macromolecules 43 (2010), pp. 1309-1318.

[23] J. Skey, H. Willcock, M. Lammens, F. Du Prez, R.K. O'Reilly, Macromolecules 43 (2010), pp. 5949-5955.

[24] C. Luo, Acta Polymerica Sinica. 7 (2016), pp. 925-930.

[25] C. Luo, Y. Liu, Z. Li, Macromolecules 43 (2010), pp. 8101-8108.

[26] D. Yu, C. Luo, W. Fu, Z. Li, Polym. Chem. 5 (2014), pp. 4561-4568.

[27] C. Luo, B. Zhao, Z. Li, Polymer 53 (2012), pp. 1725-1732.

[28] V. Lemieux, P.H.H.M. Adams, J.C.M. van Hest, Chem. Commun. 46 (2010), pp. 3071-3073.

[29] L. Ayres, K. Koch, P. Adams, J.C.M. van Hest, Macromolecules 38 (2005), pp. 1699-1704.

[30] X. Tang, X. Liang, L. Gao, X. Fan, Q. Zhou, J. Polym. Sci., Part A: Polym. Chem. 48 (2010), 
pp. 2564-2570.

[31] V. Bütün, S.P. Armes, N.C. Billingham, Polymer 42 (2001), pp. 5993-6008.

[32] F.A. Plamper, M. Ruppel, A. Schmalz, O. Borisov, M. Ballauff, A.H.E. Müller, Macromolecules 40 (2007), pp. 8361-8366.

[33] S.-H. Jung, H.-Y. Song, Y. Lee, H.M. Jeong, H.-i. Lee, Macromolecules 44 (2011), pp. $1628-1634$.

[34] X. Jiang, C. Feng, G. Lu, X. Huang, ACS Macro Lett. 3 (2014), pp. 1121-1125.

[35] X. Jiang, C. Feng, G. Lu, X. Huang, Polymer 64 (2015), pp. 268-276.

[36] Z. Song, K. Wang, C. Gao, S. Wang, W. Zhang, Macromolecules 49 (2016), pp. 162-171.

[37] K. Wang, Z.F. Song, C.G. Liu, W.Q. Zhang, Polym. Chem. 7 (2016), pp. 3423-3433.

[38] X. Tang, X. Liang, L. Gao, X. Fan, Q. Zhou, J. Polym. Sci., Part A: Polym. Chem. 48 (2010), pp. 2564-2570.

[39] A. Darabi, P.G. Jessop, M.F. Cunningham, Chem. Soc. Rev. (2016), DOI:

10.1039/C5CS00873E.

[40] K. Zhou, Y. Wang, X. Huang, K. Luby-Phelps, B.D. Sumer, J. Gao, Angew. Chem., Int. Ed. 50 (2011), pp. 6109-6114.

[41] G. Moad, Y.K. Chong, A. Postma, E. Rizzardo, S.H. Thang, Polymer 46 (2005), pp. 8458-8468.

[42] J. Morcellet-Sauvage, M. Morcellet, C. Loucheux, Macromolecules 16 (1983), pp. 1564-1570.

[43] X. Wang, C. Wu, Macromolecules 32 (1999), pp. 4299-4301.

[44] Y. Cao, X.X. Zhu, J. Luo, H. Liu, Macromolecules 40 (2007), pp. 6481-6488.

[45] Y. Xia, N.A.D. Burke, H.D.H. Stöver, Macromolecules 39 (2006), pp. 2275-2283.

[46] X. Jiang, B. Zhao, J. Polym. Sci., Part A: Polym. Chem. 45 (2007), pp. 3707-3721.

[47] Y. Zhang, S. Furyk, D.E. Bergbreiter, P.S. Cremer, J. Am. Chem. Soc. 127 (2005), pp. 14505-14510. 
[48] D. Han, X. Tong, O. Boissière, Y. Zhao, ACS Macro Lett. 1 (2012), pp. 57-61. 


\section{Graphical Abstract:}

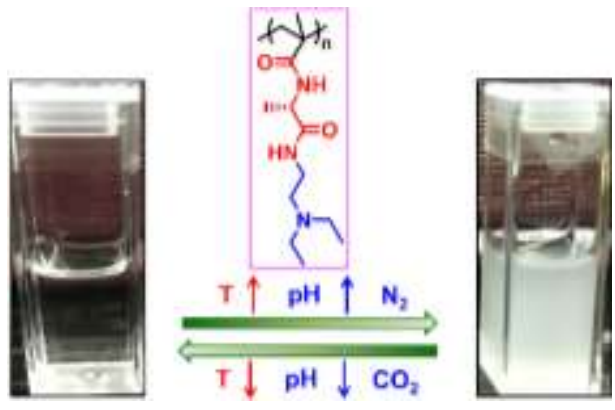

